\title{
A comparison of flow cytometry detection of minimal residual disease and chimerism kinetics in chronic lymphocytic leukemia patients after allogeneic hematopoietic stem cell transplantation
}

\author{
Adriana Plesa ${ }^{1}$, Xavier Thomas ${ }^{2}$, Quoc Hung Le$^{2}$, Anne-Sophie Michallet ${ }^{4}$, Valérie Dubois ${ }^{3}$, Charles \\ Dumontet $^{1}$, Mauricette Michallet ${ }^{2}$
}

\footnotetext{
${ }^{1}$ Laboratory of Hematology, Hospices Civils de Lyon, Edouard Herriot Hospital, Lyon, France;

${ }^{2}$ Hematology Department, Hospices Civils de Lyon, Edouard Herriot Hospital, Lyon, France;

${ }^{3}$ Laboratory of Histocompatibility, Etablissement Français du Sang, Lyon, France;

${ }^{4}$ Hematology Department, Hospices Civils de Lyon, Lyon-Sud Hospital, Pierre-Bênite, France.

Email: xavier.thomas@,chu-lyon.fr
}

Received 29 September 2010; revised 16 October 2011; accepted 18 October 2010.

\begin{abstract}
Determination of minimal residual disease (MRD) remains crucial for the follow-up after therapy in chronic lymphocytic leukemia (CLL) patients. Chimerism was assessed by short tandem repeat (STR)PCR and single nucleotide polymorphisms (SNP)PCR, and MRD by a multicolor flow cytometric approach in 12 consecutive patients with CLL after they received allogeneic stem cell transplantation (SCT). Overall, 11 patients achieved MRD flow negativity [10 had full donor chimerism (FDC) and one had mixed chimerism (MC)]. Only one patient remained with MRD flow positivity and displayed MC. Fiftysix samples were concomitantly studied by both chimerism and MRD flow. A significant correlation was observed between MRD flow data and chimerism in both $P B$ and $B M$ by using a mixed effect linear regression $(p<0.001)$. Flow cytometry approach of MRD can be easily combined with chimerism during the follow-up post-allogeneic SCT. Both techniques appeared complementary for guiding post-transplant immunomodulation.
\end{abstract}

Keywords: Chronic Lymphocytic Leukemia, Allogeneic Stem Cell Transplantation, Minimal Residual Disease, Chimerism

\section{INTRODUCTION}

Important advances have been made over the past two decades in the prognosis and treatment of chronic lymphocytic leukemia (CLL) [1]. New therapeutic approaches aim to induce molecular remission. The better quality of response, provided by novel agents and new therapeutic approaches, requires necessarily more sensitive tools for precise remission assessment [2-7]. The evaluation of response to treatment in CLL is currently based on the National Cancer Institute (NCI) criteria [8]. Several studies have demonstrated that CLL patients achieving response at a molecular level without any detectable minimal residual disease (MRD) have a longer survival [5-9]. Using a very high sensitive flow cytometry technique, several groups have shown that patients in complete remission (CR) with detectable MRD have an increased risk of early relapse $[3,6]$. In this setting, bone marrow biopsy appeared to be less sensitive than flow cytometry [10]. Conversely, similar results have been shown with real-time quantitative (RTQ) polymerase chain reaction (PCR) and MRD flow monitoring in terms of leukemia cell clearance kinetics and timing for reaching MRD negativity [6].

Because of the relatively advanced age of patients with CLL, no consistent efforts have been made to conduct stem cell transplantation (SCT) with use of allogeneic donors. However, allogeneic SCT remains the only curative treatment for CLL in younger adults. In the setting of allogeneic SCT, molecular techniques for chimerism determination are routinely used for engraftment follow-up and early prediction of post-transplant relapse. They have been routinely used in parallel with MRD analysis by flow cytometry. Furthermore, allogeneic SCT after reduced intensity conditioning (RIC) has been recently developed as a safer approach for older patients and has therefore emerged as the treatment of choice for older high-risk CLL patients requiring transplantation [11]. In this setting, the significance of chimerism and 
MRD flow cytometry needs to be reevaluated. The aim of the present study was to compare chimerism and MRD flow cytometry level after allogeneic SCT in order to fully document $\mathrm{CR}$ and to guide immunomodulation by donor lymphocyte infusions (DLI).

\section{PATIENTS AND METHODS}

\subsection{Patient Characteristics}

Between 2000 and 2007, 12 CLL patients (9 males, 3 females) with a median age of 51 years (range $31-66$ years) underwent allogeneic SCT in our institution. At the time of diagnosis, 2 patients were in stage A, 6 in stage $B$ and 4 in stage $C$ according to Binet's classification [12]. Matutes' score was noted at 5 for 7 patients, 4 for 2 patients and 3 for the last 3 patients. Before allogeneic SCT, one patient received one line of conventional therapy and 11 received more than 2 lines: 11 patients received fludarabine-based therapeutic regimens, 6 received immunotherapy with rituximab and/or alemtuzumab, 3 have previously been auto-transplanted, and one has received a first allogeneic SCT. At the time of allogeneic transplant, 3 patients were in CR, while 7 were in partial remission (PR) and 2 in progressive disease. Response criteria were defined according to $\mathrm{NCI}$ guidelines for CLL [8].

\subsection{Transplant Procedure}

Patients underwent SCT from HLA identical sibling donors after signing a written informed consent. Transplant characteristics are summarized in Table 1. Regarding hematopoietic stem cell source, 9 patients received $\mathrm{PB}$ stem cells and 3 patients BM stem cells. One patient was allografted twice. For the second allogeneic transplant, he received PB stem cells. Regarding conditioning regimen, 2 patients received a myeloablative regimen combining total body irradiation (TBI) (12 grays) with

Table 1. Transplant characteristics of the 12 CLL patients.

\begin{tabular}{|c|c|c|c|c|c|c|c|c|c|c|c|c|c|}
\hline $\begin{array}{c}\text { Patient } \\
\#\end{array}$ & Age & $\begin{array}{l}\text { BINET } \\
\text { Stage }\end{array}$ & $\begin{array}{l}\text { Disease } \\
\text { status at } \\
\text { Trans- } \\
\text { plant }\end{array}$ & $\begin{array}{l}\text { Conditioning } \\
\text { regimens }\end{array}$ & HSC & $\begin{array}{c}\text { Sex } \\
\text { matched }\end{array}$ & $\begin{array}{l}\text { Diagno- } \\
\text { sis to } \\
\text { AlloSCT } \\
\text { (years) }\end{array}$ & $\begin{array}{l}\mathrm{N} \text { of pre- } \\
\text { vious } \\
\text { therapeutic } \\
\text { lines }\end{array}$ & $\begin{array}{l}\text { Previ- } \\
\text { ous } \\
\text { SCT }\end{array}$ & $\begin{array}{l}\text { Acute } \\
\text { GVHD }\end{array}$ & $\begin{array}{l}\text { Chronic } \\
\text { GVHD }\end{array}$ & $\begin{array}{c}\text { Parallel } \\
\text { evaluation } \\
\text { MRD vs } \\
\text { chimerism at } \\
1 \text { year after } \\
\text { SCT }\end{array}$ & $\begin{array}{l}\text { Outcome at last } \\
\text { follow-up }\end{array}$ \\
\hline \multirow[t]{2}{*}{$\mathrm{P} \# 1$} & 36 & B & $\mathrm{CR}$ & $\begin{array}{c}\text { CYT } 120+12 \\
\text { TBI }\end{array}$ & $\mathrm{BM}$ & R F/D M & 3.3 & 2 & & No & No & $\mathrm{ND} / \mathrm{FDC}$ & $\begin{array}{l}\text { Alive, } 82^{+} \text {months, } \\
\text { (MRD neg / FDC) }\end{array}$ \\
\hline & 49 & B & PR & CYT $200+$ ATG & PBSC & $\mathrm{R} \mathrm{M} / \mathrm{D} \mathrm{F}$ & 2 & 2 & & Grade 1 & $\begin{array}{c}\text { Exten- } \\
\text { sive }\end{array}$ & $\mathrm{ND} / \mathrm{FDC}$ & $\begin{array}{l}\text { Alive, } 80^{+} \text {months, } \\
\text { ( MRD neg / FDC) }\end{array}$ \\
\hline $\mathrm{P} \# 3$ & 38 & B & PR & $\begin{array}{c}\text { CYT } 120+12 \\
\text { TBI }\end{array}$ & $\mathrm{BM}$ & $\begin{array}{c}\text { Sex } \\
\text { matched }\end{array}$ & 1 & 1 & & Grade 2 & Limited & ND/FDC & $\begin{array}{l}\text { Alive, } 77^{+} \text {months, } \\
\text { ( MRD neg / FDC) }\end{array}$ \\
\hline $\mathrm{P} \# 4$ & 49 & $\mathrm{C}$ & $\begin{array}{c}\text { PD } \\
\text { (Relapse) }\end{array}$ & Fluda + 2 TBI & PBSC & $\begin{array}{c}\text { Sex } \\
\text { matched }\end{array}$ & 4.1 & 2 & Auto & Grade 1 & Limited & $\mathrm{ND} / \mathrm{FDC}$ & $\begin{array}{c}\text { Alive, } 74^{+} \text {months, } \\
\text { (MRD neg/FDC ) }\end{array}$ \\
\hline P \# 6 & 50 & $\mathrm{C}$ & PR & Fluda + 2 TBI & PBSC & $\begin{array}{c}\text { Sex } \\
\text { matched }\end{array}$ & 5.7 & 5 & Auto & Grade 2 & Limited & $\mathrm{Neg} / \mathrm{FDC}$ & $\begin{array}{c}\text { Alive, } 52^{+} \text {months, } \\
\text { (MRD neg/FDC) }\end{array}$ \\
\hline $\mathrm{P} \# 7$ & 55 & B & $\mathrm{CR}$ & Fluda + 2 TBI & PBSC & $\mathrm{R} \mathrm{M} / \mathrm{D} \mathrm{F}$ & 7.9 & 3 & & No & $\begin{array}{l}\text { Exten- } \\
\text { sive }\end{array}$ & $\mathrm{Neg} / \mathrm{FDC}$ & $\begin{array}{c}\text { Death, } 28^{+} \text {months, } \\
\text { (MRD neg/FDC) }\end{array}$ \\
\hline P\# 8 & 54 & $\mathrm{C}$ & PD & $\begin{array}{c}\text { Fluda + Busulfan } \\
+ \text { ATG }\end{array}$ & PBSC & $\mathrm{R} \mathrm{M} / \mathrm{D} \mathrm{F}$ & 13 & 7 & Allo & Grade 3 & $\begin{array}{l}\text { Exten- } \\
\text { sive }\end{array}$ & $\mathrm{Neg} / \mathrm{FDC}$ & $\begin{array}{c}\text { Alive, } 24^{+} \text {months, } \\
\text { (MRD neg/FDC) }\end{array}$ \\
\hline P \# 9 & 59 & A & PR & CYT $200+$ ATG & PBSC & $\begin{array}{c}\text { Sex } \\
\text { matched }\end{array}$ & 5 & 2 & & Grade 2 & Limited & $\begin{array}{l}\mathrm{Neg} / \mathrm{MC} \\
\text { stable }\end{array}$ & $\begin{array}{l}\text { Alive, } 29^{+} \text {months, } \\
\text { (MRD neg/MC }\end{array}$ \\
\hline P \# 10 & 66 & A & PR & Fluda + 2 TBI & PBSC & RM/D F & 8.9 & 5 & & Grade 1 & No & Neg/FDC & $\begin{array}{l}\text { Dead, } 3^{+} \text {months, } \\
\text { (MRD neg / FDC) }\end{array}$ \\
\hline $\mathrm{P} \# 11$ & 60 & B & PR & Fluda + 2 TBI & $\mathrm{BM}$ & $\begin{array}{c}\text { Sex } \\
\text { matched }\end{array}$ & 5.8 & 3 & Auto & Grade 3 & ND & $\mathrm{Neg} / \mathrm{FDC}$ & $\begin{array}{l}\text { Alive, } 3^{+} \text {months, } \\
\text { (MRD neg/FDC) }\end{array}$ \\
\hline
\end{tabular}

Abbreviations: $\mathrm{CR}=$ complete response, $\mathrm{PR}=$ partial response, $\mathrm{PD}=$ progressive disease, $\mathrm{CYT} 120=$ cyclophosphamide $(60 \mathrm{mg} / \mathrm{kg} \times \mathrm{x} 2$ days $), \mathrm{CYT} 200=$ cyclophosphamide $(50 \mathrm{mg} / \mathrm{kg} \times 5$ days $), 12 \mathrm{TBI}=$ total body irradiation $(12$ Grays $), 2 \mathrm{TBI}=$ total body irradiation $(2 \mathrm{Grays}), 6 \mathrm{TBI}=$ total body irradiation $(6$ Grays), $\mathrm{SCT}=$ stem cell transplantation, $\mathrm{ATG}=$ anti-thymoglobulins, $\mathrm{BM}=$ bone marrow, $\mathrm{PBSC}=$ peripheral blood stem cells, $\mathrm{R}=$ recipient, $\mathrm{D}=\mathrm{donor}, \mathrm{F}=$ female, $\mathrm{M}=$ male, $\mathrm{GVHD}=$ graft-vs-host disease, $\mathrm{FU}=$ follow-up, $\mathrm{FDC}=$ full donor chimerism, $\mathrm{MC}=$ mixed chimerism, $\mathrm{ND}=$ not done, pos $=$ positive, neg $=$ negative, $\mathrm{MRD}=$ minimal residual disease, Auto $=$ autologous $\mathrm{SCT}, \mathrm{Allo}=$ allogeneic SCT. 
cyclophosphamide $(60 \mathrm{mg} / \mathrm{kg} /$ day $\times 2$ days $)$ and 10 patients received a RIC constituted of either fludarabine $\left(30 \mathrm{mg} / \mathrm{m}^{2} /\right.$ day $\times 3$ days $)$ and TBI $(2$ grays $)(\mathrm{n}=6)$, or anti-thymoglobulines (ATG) $(2.5 \mathrm{mg} / \mathrm{kg} /$ day $\times 5$ days $)$ or fludarabine $\left(30 \mathrm{mg} / \mathrm{m}^{2} /\right.$ day $\times 5$ days $)$, busulfan $(4$ $\mathrm{mg} / \mathrm{kg} /$ day $\times 2$ days $)$ and ATG $(2.5 \mathrm{mg} / \mathrm{kg} /$ day $\times 2$ days $)$ and cyclophosphamide $(50 \mathrm{mg} / \mathrm{kg} /$ day $\times 4$ days $)(\mathrm{n}=3)$, $(\mathrm{n}=1)$. Graft-versus-host disease (GVHD) prophylaxis consisted of either cyclosporine alone $(\mathrm{n}=1)$, or cyclosporine and mycophenolate mofetil (MMF) $(\mathrm{n}=7)$, or cyclosporine and methotrexate $(n=4)$. Five patients were sex-mismatched with the recipient (4 females to males, and one male to female) and for the second transplant the male recipient received PB stem cells from another HLA identical sister. Regarding cytomegalovirus (CMV) status, 4 pairs were CMV mismatched $\left(1 \mathrm{D}^{-} / \mathrm{R}^{+}\right.$, $\left.3 \mathrm{D}^{+} / \mathrm{R}^{-}\right), 4$ pairs were $C M V$ positive $\left(\mathrm{D}^{+} / \mathrm{R}^{+}\right)$and 4 pairs were $C M V$ negative $\left(D^{-} / R^{-}\right)$. In the case with a second allogeneic SCT, the pair was $\mathrm{D}^{+} / \mathrm{R}^{+}$. Four patients presented an $\mathrm{ABO}$ incompatibility (3 minor and one major).

\subsection{Graft-versus-Host Disease}

After transplant, 6 patients developed a grade $2(\mathrm{n}=3)$ or $3(\mathrm{n}=3)$ acute GVHD and 8 patients developed a chronic GVHD (4 limited and 4 extensive). The patient allografted twice presented after the second SCT, a grade 2 acute GVHD followed by a limited chronic GVHD. At the time of the last follow-up [median, 53 months (range: 3 - 82 months)], 2 patients had died from infections, while 10 were still alive.

\subsection{Chimerism Analyses}

Chimerism was documented on days $30,60,90$, and on months 6 and 12 during the first year following SCT, and then twice a year. Chimerism was assessed on total $\mathrm{PB}$ cells, total $\mathrm{BM}$ cells, selected $\mathrm{CD}^{+}$cells, and selected $\mathrm{CD} 19^{+}$cells by short tandem repeat (STR)-PCR (sensitivity [S]: $5 \%$ ) or by single nucleotide polymerphisms (SNP) real-time (RT)-PCR (S: 0.2\%) [13,14]. Overall, $192 \mathrm{~PB}$ chimerisms and 59 BM chimerisms were performed with a median of $16 \mathrm{~PB}$ chimerisms (range: $3-41$ ) and 5 BM chimerisms (range: $1-16$ ) per patient. Chimerism was assessed by STR-PCR from 2000 to 2005 and by RT-PCR afterwards. The percentage of recipient cells (RC) in each sample was determined by using STR analysis with Promega multiplex kits (CTTV, FFFL and gamma STR) based fluorescent analysis of repetitive sequences peak areas. Mixed chimerism was defined by the presence of at least $5 \%$ RC. The RT quantitative PCR chimerism assay, using the Taqman technology and ABI 7700 (Applera), has been previously described [14]. Here, mixed chimerism was defined by the presence of at least $0.1 \%$ of RC.

\subsection{MRD Flow Cytometry Analysis}

MRD flow cytometry was assessed, every 3 months during the first year following transplant, and every 6 months afterwards, on PB and/or BM cells by an international standardized multicolor approach (S: 0.01\%) [7]. Overall, 65 PB MRD flows, and 23 BM MRD flows were performed with a median of 5 PB MRD analyses (range: $1-20$ ), and 2 BM MRD analyses (range: $1-5$ ) per patient. Patients were considered MRD flow positive if the detected MRD CLL levels were $\geq 10^{-4}$. Specificity and sensibility of the technique were validated by using a series of 10 normal PB and BM samples. MRD was studied by using quadruple antigenic combinations: CD20-FITC/ CD79b-PE/ CD19-PerCP-Cy5.5/ CD5-APC, CD43-FITC/ CD79b-PE/ CD19-PerCP-Cy5.5 CD5-APC, Kappa-FITC/Lambda-PE/CD19-PerCP-Cy5.5/CD5-APC, and CD22-FITC/ CD5-PE/ CD19-PerCP-Cy5.5/ CD38 APC. In BM samples, the combination containing CD38 was used to better discriminate CLL cells from B-cell precursors (hematogones). In addition to daily calibrations using Calibrite beads (Becton Dickinson) and FACSComp v4.2 software (Becton Dickinson), isotype controls were used to optimize light scatter, amplification and threshold. For our study, at least 50 CLL cells forming a population in light scatter in at least two of the three MRD tests (excluding $\mathrm{K} / \mathrm{L}$ antigens) were required as evidence for MRD (absolute specificity threshold). The result was classified as positive if the level was above the mean number of the false positive cells in healthy controls. A median of 300,000 leucocytes/samples (range 50,000 and 600,000) depending on time point was acquired using CellQuest Pro software (Becton Dickinson) and analyzed using Paint-A-Gate software (Becton Dickinson). The complete gating strategy for identification of CLL specific phenotype (MRD flow assay) has been previously described, using a $\mathrm{CD} 43^{+}$as fourth criterion for CLL cells [5].

\subsection{Statistical Analysis}

Kaplan Meier product-limit estimates were used to assess the probability of overall survival (OS). The relationship between chimerism and MRD flow assay was evaluated by a linear mixed effects model [15]. The model included MRD as the resulting variable, chimerism as the fixed effect and patients as the random effect. An analysis was performed for BM and a second analysis was performed for PB. Significative effects were defined by $p$ values of less than 0.05 . All analyses were performed using Splus 6.2 (Insightful, Seattle).

\section{RESULTS}

At the time of study, the median follow-up was 53 months. Two patients had died from infection, while 10 
were still alive. The 2 patients who died displayed MDR negativity and had FDC. Among alive patients, 9 were with MRD flow negativity ( 8 had FDC and one had MC), while one was with MRD flow positivity and displayed MC. Two hundred and fifty-one samples were tested for chimerism (192 from $\mathrm{PB}$ and 59 from $\mathrm{BM}$ ) and 88 for MRD flow cytometry (65 from $\mathrm{PB}$ and 23 from $\mathrm{BM}$ ). Only 56 samples were studied at the same time point, and were then used for comparing quantitative MRD flow cytometry and chimerism.

\subsection{Chimerism Analysis}

Comparison of results obtained from PB and BM samples showed $93 \%$ of concordance. The conversion of mixed chimerism (MC) to full donor chimerism (FDC) at Day 30 post-transplant was observed in 5 cases. The conversion was observed between Day 30 and Day 120 in 3 cases and after Day 120 in one case. Three patients never converted to FDC (patient \# 12 had not enough follow-up, patient \# 9 remained in stable $\mathrm{MC}$ at 3 months post-transplant, and patient \# 8, who relapsed after a first RIC SCT, underwent then a second allogeneic SCT from another HLA identical sister allowing a durable FDC). Eleven patients had their chimerism done on selected cells, of whom 4 with MC (Table 2).

\subsection{MRD Flow Cytometry Analysis}

Comparison of results obtained from PB and BM samples showed $100 \%$ of concordance. Because of the recent introduction of MRD flow assay in the clinical routine, longitudinal data during the first year post-transplant were only available for 8 patients. They showed MRD flow negativity at Day 30 in one case, at Day 90 in another case, at Day 120 in 3 cases, and at 12 months post-transplant in 2 cases. One patient remained positive, but displayed decreasing MRD flow levels. Regarding the 4 patients without optimal longitudinal follow-up, all patients achieved MRD negativity but were only assessed at time points for which samples were available (on months 30, 36, 42, and 48 post-transplant, respecttively). Patient \# 8 never achieved MRD negativity after the first transplant, but showed a low MRD level at 12 months and MRD negativity 24 months after the second SCT.

\subsection{Comparison of Chimerism and MRD Kinetics}

Results are summarized in Table 2. Regarding kinetics

Table 2. Chimerism and MRD kinetics (12 patients).

\begin{tabular}{|c|c|c|c|c|c|c|c|c|c|c|c|c|c|c|c|c|c|c|c|c|}
\hline \multirow{3}{*}{$\begin{array}{c}\text { Patient } \\
\# \\
\end{array}$} & \multicolumn{6}{|c|}{ Days +21 to +56 (1-2 months) } & \multicolumn{4}{|c|}{ Days +100 (3 months) } & \multicolumn{6}{|c|}{ Days +180 to +270 (6-9 months) } & \multicolumn{4}{|c|}{ Days +360 (1 year) } \\
\hline & \multicolumn{4}{|c|}{ Chimerism } & \multirow{2}{*}{$\begin{array}{c}\text { MRD } \\
\text { flow } \\
\text { PB/BM }\end{array}$} & \multirow[b]{2}{*}{ PB } & \multicolumn{2}{|c|}{ Chimerism } & \multirow{2}{*}{\multicolumn{2}{|c|}{$\begin{array}{cc}\text { MRD } \\
\text { flow } \\
\text { CD19 } & \text { PB/BM }\end{array}$}} & \multirow[b]{2}{*}{ PB } & \multicolumn{2}{|c|}{ Chimerism } & \multicolumn{3}{|c|}{$\begin{array}{l}\text { MRD } \\
\text { flow }\end{array}$} & \multicolumn{2}{|c|}{ Chimerism } & \multirow{2}{*}{\multicolumn{2}{|c|}{$\begin{array}{r}\begin{array}{r}\text { MRD } \\
\text { flow }\end{array} \\
19 \text { PB/BM }\end{array}$}} \\
\hline & PB & $\mathrm{BM}$ & CD3 & CD19 & & & $\mathrm{BM}$ & CD3 & & & & $\mathrm{BM}$ & CD3 & CD19 & $\mathrm{PB} / \mathrm{BM}$ & PB & $\mathrm{BM}$ & CD3 & & \\
\hline 1 & $\circ$ & & & & & ○ & & & & & $\circ$ & & & & & ० & $\circ$ & & & \\
\hline 2 & $\bullet$ & $\bullet$ & & & & ○ & $\circ$ & & & & $\circ$ & $\circ$ & & & & $\circ$ & $\circ$ & $\circ$ & & \\
\hline 3 & ○ & ○ & & & & $\circ$ & & & & & $\circ$ & & & & & ○ & $\circ$ & $\circ$ & & \\
\hline 4 & $\bullet$ & $\bullet$ & & & & $\circ$ & $\circ$ & $\circ$ & & & $\circ$ & $\circ$ & $\circ$ & & & ० & $\circ$ & $\circ$ & & \\
\hline 5 & $\circ$ & $\circ$ & $\circ$ & & & $\circ$ & $\circ$ & ० & & & $\circ$ & $\circ$ & $\circ$ & & $\square / \mathbf{N D}$ & ० & $\circ$ & $\circ$ & & $\square / \square$ \\
\hline 6 & $\bullet$ & ० & • & & & ○ & $\circ$ & ○ & & & ○ & ○ & ○ & & $\square / \square$ & ○ & ○ & ○ & & $\square / \mathbf{N D}$ \\
\hline 7 & • & $\bullet$ & • & & ND/ם & & & • & & -/ND & & ○ & ○ & & $\square / \square$ & O & o & ○ & & $\square / \square$ \\
\hline $\begin{array}{c}8 \\
\text { SCT } 1\end{array}$ & & $\bullet$ & $\bullet$ & & ND/ש & & $\bullet$ & • & & a/ND & & $\bullet$ & $\bullet$ & & "/ND & • & $\circ$ & o & & $\mathbf{m} / \mathbf{N D}$ \\
\hline $\begin{array}{c}8 \\
\text { SCT } 2\end{array}$ & $\bullet$ & $\bullet$ & $\bullet$ & & $\square / \square$ & $\bullet$ & $\bullet$ & $\bullet$ & & ND/m & $\bullet$ & $\bullet$ & $\circ$ & $\bullet$ & $\square / \square$ & ० & $\circ$ & o & ० & $\square / \square$ \\
\hline 9 & • & $\bullet$ & $\bullet$ & & ND/ש & • & $\bullet$ & $\bullet$ & & ND/a & $\bullet$ & & $\bullet$ & & $\square / \square$ & • & • & $\bullet$ & ○ & $\square / \square$ \\
\hline 10 & O & & O & & $\square / \square$ & & & & & & & & & & & & & & & \\
\hline 11 & • & $\bullet$ & & & a/घ & ○ & $\circ$ & ○ & & $\square / \square$ & & & & & & & & & & \\
\hline 12 & $\bullet$ & $\bullet$ & & & ND/a & $\bullet$ & $\bullet$ & $\bullet$ & $\bullet$ & $\square / \square$ & & & & & & & & & & \\
\hline
\end{tabular}

o complete donor chimerism $(<5 \%$ donor cells by STR and $<0,2 \%$ donor cells by SNP RT-PCR); $\bullet$ mixed chimerism; $\square$ negative MRD flow $($ CLL cells $<1 \mathrm{x}$ $10^{-4}$ by MRD flow); $\mathbf{m}$ positive MRD; ND, not done. 
of disappearance of a detectable disease, a strict concordance was established between MRD flow assay and chimerism in 50 of the 56 available samples (89\%). Analyses, using a mixed effect linear regression to account for repeated measures for each patient, showed a significant correlation between MRD flow and chimerism $(p<0.001)$ tested on PB samples and between MRD flow and chimerism $(\mathrm{p}<0.001)$ tested on BM samples. The 6 non concordant samples were all harvested in a single patient. In this case, a decreasing percentage of RC was observed, but remained stable until the sixth month post-transplant [MC $<1 \%$ (range: $0.2-0.9$ )] During the same time, MRD flow negativity persisted from 12 months post-transplant until the time of last follow-up.

\section{DISCUSSION}

Important advances have been made in the prognosis and treatment of CLL over the past two decades [1]. With conventional therapy, a large proportion of patients can achieve CR [16,17]. However, allogeneic SCT remains the only curative therapy $[18,19]$. The number of allogeneic SCT performed in this disease is therefore susceptible to significantly increase, mainly due to the recent development of RIC allogeneic SCT in older patients [20,21]. New technologies such as 4-color flow cytometry and RT quantitative PCR have identified the persistance of a detectable disease in patients considered in CR according to international guidelines [5]. The absence of detectable leukemia by these sensitive tests seems to be an important prognostic factor [9,22], since it has been shown correlated with a longer survival. A strong concordance has been described between these two techniques for MRD evaluation, with a limit of detection of one malignant cell per 10.000 total cells and $100 \%$ applicability of MRD flow assay.

The present series, summarizing our experience in the setting of allogeneic SCT in CLL, tends to confirm previous reports. All patients, except one, showed MRD negativity when tested by flow cytometry. Ten patients obtained FDC, while 2 only achieved MC. We first established a positive concordance between $\mathrm{PB}$ and $\mathrm{BM}$ for both chimerism and MRD flow. Secondly, a positive concordance $(89 \%)$ was confirmed between determination of residual disease by both flow cytometry and chimerism. Two types of conversion after transplantation were described for both chimerism and MRD flow: an earlier conversion following transplant and a later conversion. The kinetics of conversion to FDC was faster than kinetics of disappearance of detectable disease as observed by using flow cytometry: $42 \%$ of documented cases converted to FDC at Day 30, while at the same time only $12 \%$ of assessable cases were MRD negative by flow cytometry. Flow cytometry detection of MRD seems therefore more sensitive. Interestingly, detection of MRD by flow cytometry seemed also more acurate than total cell chimerism evaluation among the non concordant samples coming from one single patient. However, when considering lineage specific chimerism by selecting $\mathrm{CD}_{1} 9^{+}$cells for instance, a full donor profile quite concordant with MRD flow negativity was observed.

However, as no relapses were reported in the followup of our series, after reaching negativity, it is difficult to judge the relevance of the suggested use of MRD instead of chimerism in the long-term follow-up. The two techniques must certainly be considered as complementary for documenting MRD in CLL patients after allogeneic SCT and guiding immunomodulation.

The quantitative techniques used for the assessment of MRD and chimerism seemed therefore interesting tools for documenting disease and transplant status in CLL, as it has been also previously demonstrated in other hematological malignancies [23].

In the transplant setting for CLL patients, MRD detection should be considered as a surrogate marker for disease eradication. Our results are in agreement with previously published data showing the importance of MRD eradication assessed by flow cytometry during the posttransplant follow-up in CLL $[2,3,6,10]$. However we reported only on a small series heterogeneous in terms of conditioning regimens, and chimerism results could be different after myeloablative and non-myeloablative conditioning. MRD flow appeared more specific than total cell chimerism evaluation. MRD flow assay also appeared as a faster and less expensive technique for guiding adoptive immunotherapy or treatment abstention after allogeneic transplantation. Nevertheless, both techniques appeared complementary, most specially when studying lineage specific documentation. Another important point is to consider a strict schedule of evaluation.

\section{REFERENCES}

[1] Dighiero, G. and Hamblin, T.J. (2008) Chronic lymphocytic leukaemia. Lancet, 371, 1017-1029. doi:10.1016/S0140-6736(08)60456-0

[2] Moreton, P., Kennedy, B., Lucas, G., Leach, M., Rassam, A.M.B., Haynes, A., et al. (2005) Eradication of minimal residual disease in B-cell chronic lymphocytic leukaemia after Alemtuzumab therapy is associated with prolonged survival. Journal of Clinical Oncology, 23, 2971-2979. doi:10.1200/JCO.2005.04.021

[3] Maloum, K., Sutton, L., Baudet, S., Laurent, C., Bonnemye, P., Magnac, C., et al. (2002) Novel flow-cytometric analysis based on $\mathrm{B} \mathrm{CD5}^{+}$subpopulations for the evaluation of minimal residual disease in chronic lymphocytic leukaemia. British Journal of Haematology, 119, 970-975. 
[4] Dreger, P., Ritgen, M., Bottcher, S., Schmitz, N. and Kneba, M. (2005) The prognostic impact of minimal residual disease assessment after stem cell transplantation for chronic lymphocytic leukaemia: Is achievement of molecular remission worthwhile? Leukemia, 19, 1135-1138. doi:10.1038/sj.leu.2403800

[5] Böttcher, S., Ritgen, M., Pott, C., Bruggemann, M., Raff, T., Stilgenbauer, S., et al. (2004) Comparative analysis of minimal residual disease detection using four-color flow cytometry, consensus IgH-PCR, and quantitative $\operatorname{IgH}$ PCR in CLL after allogeneic and autologous stem cell transplantation. Leukemia, 18, 1637-1645. doi:10.1038/sj.leu.2403478

[6] Ritgen, M., Böttcher, S., Stilgenbauer, S., Bunjes, D., Schubert, J., Cohen, S., et al. (2008) Quantitative MRD monitoring identifies distinct GVL response patterns after allogeneic stem cell transplantation for chronic lymphocytic leukemia: Results from the GCLLSG CLL3X trial. Leukemia, 22, 1377-1386. doi:10.1038/leu.2008.96

[7] Rawstron, A.C., Villamor, N., Ritgen, M., Bottcher, S., Ghia, P., Zehnder, J.L., et al. (2007) International standardized approach for flow cytometric residual disease monitoring in chronic lymphocytic leukemia. Leukemia, 21, 956-964.

[8] Cheson, B.D., Bennett, J.M., Grever, M., Kay, N., Keating, M.J., O’Brien, S., et al. (1996) National Cancer Institured-sponsored Working Group guidelines for chronic lymphocytic leukemia: Revised guidelines for diagnosis and treatment. Blood, 87, 4990-4997.

[9] Moreno, C., Villamor, N., Colomer, D., Esteve, J., Giné, E., Muntanola, A., et al. (2006) Clinical significance of minimal residual disease, as assessed by different techniques, after stem cell transplantation for chronic lymphocytic leukemia. Blood, 107, 4563-4569. doi:10.1182/blood-2005-09-3634

[10] Maloum, K., Charlotte, F., Divine, M., Cazin, B., Lesty, C. and Merle-Béral, H. (2006) A comparison of the sensitivity of flow cytometry and bone marrow biopsy in the detection of minimal residual disease in chronic lymphocytic leuke- mia. Haematologica, 91, 860-861.

[11] Dreger, P., Corradini, P., Kimby, E., Michallet, M., Milligan, D., Schetelig, J., et al. (2007) Chronic Leukemia Working Party of the EBMT. Indications for allogeneic stem cell transplantation in chronic lymphocytic leukemia: the EBMT transplant consensus. Leukemia, 21, 12-17. doi:10.1038/sj.leu.2404441

[12] Binet, J.L., Auquier, A., Dighiero, G., Chastang, C., Piguet, H., Goasguen, J., et al. (1981) A new prognostic classification of chronic lymphocytic leukemia derived from a multivariate survival analysis. Cancer, 48, 198206.doi:10.1002/1097-0142(19810701)48:1<198::AID-C NCR2820480131>3.0.CO;2-V

[13] Thiede, C., Florek, M., Bornhauser, M., Ritter, M., Mohr, B., Brendel, C., et al. (1999) Rapid quantification of mixed chimerism using multiplex amplification of short tandem repeat markers and fluorescence detection. Bone Marrow Transplant, 23, 1055-1060. doi:10.1038/sj.bmt.1701779

[14] Alizadeh, M., Bernard, M., Danic, B., Dauriac, C., Birebent, B., Lapart, C., et al. (2002) Quantitative assessment of hematopoietic chimerism after bone marrow transplantation by real-time quantitative polymerase chain reaction. Blood, 99, 4618-4625. doi:10.1182/blood.V99.12.4618

[15] Pinheiro, J.C. and Bates, D.M. (2000) Mixed-effects models in S and S-PLUS. Springer, New-York.

[16] Keating, M.J., O’Brien, S., Albitar, M., Lerner, S., Plunkett, W., Giles, F., et al. (2005) Early results of a chemoimmunotherapy regimen of fludarabine, cyclophosphamide, and rituximab as initial therapy for chronic lymphocytic leukemia. Journal of Clinical Oncology, 23, 4079-4088. doi:10.1200/JCO.2005.12.051

[17] Keating, M.J., Flinn, I., Jain, V., Binet, J.L., Hillmen, P., Byrd, J., et al. (2002) Therapeutic role of alemtuzumab (Campath-1H) in patients who have failed fludarabine: results of a large international study. Blood, 99, 35543561. doi:10.1182/blood.V99.10.3554

[18] Michallet, M., Archimbaud, E., Rowlings, P.A., Deeg, H. J., Gahrton, G., Montserrat, E., et al. (1996) HLA-identical sibling bone marrow transplants for chronic lymphocytic leukemia. Annals of Internal Medicine, 124, 311-315.

[19] Rabinowe, S.N., Soiffier, R.J., Gribben, J., Daley, H., Freedman, A.S., Daley, J., et al. (1993) Autologous and allogeneic bone marrow transplantation for poor prognosis patients with B-cell chronic leukemia. Blood, 4, 13661376.

[20] Brown, J.R., Kim, H.T., Li, S., Stephans, K., Fisher, D.C., Cutler, C., et al. (2006) Predictors of improved progression-free survival after nonmyeloablative allogeneic stem cell transplantation for advanced chronic lymphocytic leukemia. Biology of Blood and Marrow Transplant, 12, 1056-1064. doi:10.1016/j.bbmt.2006.06.004

[21] Khouri, I.F., Lee, M.S., Saliba, R.M., Anderlini, P., Couriel, D., Hosing, C., et al. (2004) Nonablative allogeneic stem cell transplantation for chronic lymphocytic leukemia: Impact of rituximab on immunomodulation and survival. Experimental Hematology, 32, 28-35. doi:10.1016/j.exphem.2003.09.021

[22] Provan, D., Bartlett-Pandite, L., Zwicky, C., Neuberg, D., Maddocks, A., Corradini, P., et al. (1996) Eradication of PCR detectable chronic lymphocytic cells is associated with improved outcome after bone marrow transplantation. Blood, 88, 2228-2235.

[23] Uzunel, M., Mattsson, J., Brune, M., Johansson, J.E., Aschan, J. and Ringden, O. (2003) Kinetics of minimal residual disease and chimerism in patients with chronic myeloid leukemia after nonmyeloablative conditioning and allogeneic stem cell transplantation. Blood, 101, 469472. doi:10.1182/blood-2002-02-0571 


\section{ABBREVIATIONS}

ATG, anti-thymoglobulines;

MRD, minimal residual disease;

$\mathrm{BM}$, bone marrow;

CLL, chronic lymphocytic leukemia;

NCI, National Cancer Institute;

CMV, cytomegalovirus;

$\mathrm{CR}$, complete remission;

OS, overall survival; $\mathrm{PB}$, pe- ripheral blood;

$\mathrm{PCR}$, polymerase chain reaction; $\mathrm{PR}$, par- tial remission;

FDC, full donor chimerism;

RC, recipient cells; RIC, reduced intensity conditioning;

DLI, donor lymphocyte infusions;

GVHD, graft-versus- host disease;

$\mathrm{MC}$, mixed chimerism;

RTQ, real-time quantitative; SCT, stem cell transplantation;

MMF, mycophe- nolate mofetil;

SNP, single nucleotide polymorphism;

STR, short tandem repeat;

TBI, total body irradiation. 